\title{
Obesity Indicators and C - reactive Protein in African and Haitian Americans with and without Type 2 Diabetes
}

\author{
Huffman FG ${ }^{1 *}$, Vaccaro JA ${ }^{1}$, Rowe TM ${ }^{1}$, Zarini GG ${ }^{1}$, Sukhram SD $^{2}$, Shaban LH $^{3}$ and Himburg $\mathbf{S}^{1}$ \\ ${ }^{1}$ Department of Dietetics and Nutrition, Robert Stempel College of Public Health and Social Work, Florida International University, USA \\ ${ }^{2}$ Department of Biology, City University of New York, USA \\ ${ }^{3}$ Department of Food Science and Nutrition, Kuwait University, Kuwait
}

"Corresponding author: Fatma G Huffman, Florida International University, Robert Stempel College of Public Health and Social Work, Department of Dietetics and Nutrition, 11200 S. W. 8th Street, AHC5 306, Miami, FL 33199, USA, E-mail: huffmanf@fiu.edu

Rec date: 29 May 2014, Acc date: 9 July 2014, Pub date: 11 July 2014

Copyright: (c) 2014 Huffman FG, et al. This is an open-access article distributed under the terms of the Creative Commons Attribution License, which permits unrestricted use, distribution, and reproduction in any medium, provided the original author and source are credited.

\begin{abstract}
Purpose: High sensitivity C-reactive protein (CRP) is a risk factor for cardiovascular disease based on finding in primarily non-Hispanic White populations. Obesity, another risk factor for cardiovascular disease, is higher in Blacks as compared to non-Hispanic Whites. The objective of this study was to assess the relationship between CRP, a marker of systemic inflammation, and obesity indicators by ethnicity, diabetes status and gender for two Black ethnicities.

Methods: Anthropometrics and venous blood were collected for African and Haitian Americans with and without type 2 diabetes in a cross-sectional study. A total of 434 participants; 190 African Americans, 244 Haitian Americans, met the inclusion criteria of CRP $\leq 10 \mathrm{mg} / \mathrm{L}$. Main effects and interactions of ethnicity, diabetes status, gender, and each obesity indicator (waist circumference, waist-to-height ratio, and body mass index) were performed using General Linear Models.
\end{abstract}

Results: African Americans were more likely to be obese, have higher CRP, and smoke as compared to Haitian Americans. Haitian Americans has a lower rate of health care coverage than African American. Having a higher education level than Haitian Americans was a protective health factor for African Americans; whereas, Haitian Americans were protected by a higher percent married as compared to African Americans. All obesity indicators were associated with CRP. All differences in CRP by ethnicity and diabetes status were negated by obesity indicators. Being female was associated with higher CRP for waist circumference and BMI models. Adjusting for health insurance, smoking, marital status and education negated the relationship of gender and CRP for waist-toheight ratio.

Conclusion: Being African American as opposed to Haitian American was a greater risk factor for obesity and inflammation. Obesity was associated with elevated CRP levels in African and Haitian Americans regardless of diabetes status. Inflammation constitutes a serious health problem for minorities with high rates of obesity.

Keywords: African Americans; Haitian Americans; C-reactive protein; Body mass index; Waist circumference; Waist-to-height ratio; Type 2 Diabetes

\section{Introduction}

Race/ethnicity and gender are risk factors for cardiovascular disease [1]. African Americans are more than six-time more likely to have coronary heart disease as compared to non-Hispanics Whites [2]. The fact that Blacks are at greater risk for cardiovascular disease, may be partially attributed to their higher rate of obesity (1.4) as compared to White, non-Hispanics (1.0) [3]. Along with race/ethnicity, obesity and systemic inflammation are risk factors for cardiovascular diseases. Waist circumference and body mass index (BMI), indicators of obesity, have predicted relative risk of coronary heart disease for men and women [4]. Albert and Ridker [5] reviewed numerous epidemiological studies and concluded that C-reactive protein (CRP), a sensitive measure of chronic, low-grade systemic inflammation, was positively associated with adverse cardiovascular events in adults. For persons with diabetes, CRP was found to be an independent risk factor for coronary heart disease related deaths [5].

Most of the studies of CRP and cardiovascular risk were conducted primarily in Caucasian cohorts. High serum CRP was independently associated with the odds of type 2 diabetes for a primarily Caucasian cohort of women from the Nurses' Health Study [6]. In a cohort of primarily Caucasian men with diabetes from the Health Professionals Follow-up Study, high serum CRP was associated with increased risk of cardiovascular events, independent of blood lipids and glycated hemoglobin (A1C) [7]. In a representative sample of US adults, the odds of gender-adjusted high CRP was greater for those with diabetes as compared to those without diabetes even after adjusting for age, gender, BMI, race/ethnicity and education [8]. Although the investigators considered race/ethnicity, their focus was on the relationship between obesity and diabetes with elevated CRP. Adiposity is thought to play a role in CRP since adipose tissue is a major source of cytokines [9] and CRP is produced by the liver in 
response to inflammatory cytokines such as interleukin-6 (IL-6) and tumor necrosis factor alpha $(\mathrm{TNF} \alpha)[10]$.

Differences in CRP were found across gender and race in a large multiethnic sample of adults between ages 30 and 65 years [11]. Blacks and women had higher CRP levels as compared to Whites and men; adjustment for obesity (BMI) negated this association for Black men, only [11]. Few studies examined the combined effect of race/ethnicity and obesity on CRP. Wee and colleagues [12] studied whether Blacks and Mexican Americans differed compared to White non-Hispanics by obesity indicators with respect to CRP in a nationally representative US sample of adults. They found only Mexican women in the largest category of waist circumference had higher CRP levels than women of other racial groups [12]. These investigators found higher BMI was associated with higher CRP regardless of ethnicity, comparing Black non-Hispanics, Mexicans, Hispanic (other than Mexican) and White non-Hispanics [12].

Blacks have been combined as a single group in most epidemiological studies and there are relatively few studies assessing health outcomes for Haitian Americans as compared to African Americans. In the context of the literature, we examined three proxy measures for obesity: BMI, waist circumference, and waist-to-height ratio by ethnicity and diabetes status with CRP for two Black ethnicities. Specifically, it was hypothesized that individuals with type 2 diabetes will have higher CRP levels than those without type 2 diabetes in consideration of obesity indicators. Since no data exist for CRP levels among Haitian Americans, it was hypothesized that their CRP levels will differ from African Americans.

\section{Materials and Methods}

\section{Participants}

This cross-sectional study was conducted on African American and Haitian Americans with and without type 2 diabetes. Two mailing lists (with and without type 2 diabetes) of addresses were purchased from Knowledge Base Marketing, Inc., Richardson, TX 75081. The randomly generated lists were used to recruit participants from Miami-Dade and Broward Counties, Florida. Knowledge Base Marketing, Inc. did not have addresses for Haitian Americans; therefore, recruitment came from community based sources. Over a 1year period, 7,550 letters were mailed to African Americans with and without type 2 diabetes. From delivered letters, $4 \%(n=256)$ responded, and 259 Haitian Americans were recruited from the community based sources. Eligible participants were invited to the Human Nutrition Laboratory at Florida International University (FIU). The study was approved by the Institutional Review Board at FIU. The purpose and protocol of the study were explained, and written consent was obtained before the start of the study. A total of 700 participants (Haitian Americans =253; African Americans =248) had complete data. The final sample size $(\mathrm{N}=434 ; 190$ African Americans, 244 Haitian Americans) included participants with CRP $\leq 10 \mathrm{mg} / \mathrm{dL}$. Participants were $\geq 35$ years of age, male and female, not pregnant or lactating, and with no other conditions associated with elevated CRP (e.g. gout, arthritis, CHD, lupus, stroke).

\section{Measures}

Subjects were asked to fill out standard questionnaires on site. Trained interviewers who were bilingual in English and Creole were present to administer the questionnaires. The questionnaire contained structured questions to gather information on each participant's demographics, smoking history, and anthropometric measurements, diabetes status, diabetes care (for diabetes only), anthropometric measurements and nutritional variables. Height and weight were measured using a SECA balance scale (Seca Corp, Columbia, MD). BMI was calculated as weight in $\mathrm{kg} / \mathrm{height}$ in $\mathrm{m} 2$. Waist circumference (WC) to the nearest $0.1 \mathrm{~cm}$ was measured horizontally with a nonstretchable measuring tape placed midway between the 12th rib and iliac crest at minimal respiration to determine central obesity [13]. Waist-to-height ratio was calculated as the waist circumference divided by height in $\mathrm{cm}$. Body mass index (BMI), calculated as the weight $(\mathrm{kg})$ divided by square of height $(\mathrm{m} 2)$. A $20 \mathrm{ml}$ venous blood was collected from each subject after an overnight fast (at least 8 hours) by a certified phlebotomist using standard laboratory techniques. Blood samples were collected into 2 tubes: K2EDTA to analyze A1C and the second a vaccutainer Serum Separator Tube (SST) for analysis of glucose. After complete coagulation (30-45 minutes), the SST was centrifuged at 2,500 RPM for 30 minutes. The serum was transferred from the spun SST into 3 labeled plastic tubes: the first tube was used for glucose analysis, and the second tube was stored at $-70{ }^{\circ} \mathrm{C}$ to be used later for High-sensitivity CRP (hs-CRP). Glucose levels were measured by hexokinase enzymatic methods by Laboratory Corporation of America, Miami, FL (LabCorp ${ }^{\circledR}$ ). Hs-CRP was analyzed at the Vascular Disease Intervention and Research Laboratory, Edmond, OK using Immulite method. The Immulite assay is a 2-site chemiluminescent enzyme immunometric assay with one monoclonal and one polyclonal anti-CRP antibody. A 1:100 manual dilution of the antibody provides a measurable range of $0.1-500 \mathrm{mg} / \mathrm{L}$ [14].

\section{Statistical Analysis}

SPSS (Version 21.0, Chicago, IL) was used for statistical analysis and $\mathrm{P}<.05$ was considered significant. Prior to analysis, all continuous variables were tested for linearity and normality using QQ plots and the Kolmogovov-Smirnov Test. Variables were transformed to achieve normality, when needed. CRP and all obesity indicators (waist circumference, body mass index (BMI) and weight-to-height ratio were natural logarithm transformed. Descriptive statistics were run comparing sociodemographics and biomarkers for participants by diabetes status and ethnicity using the student t-test. General Linear Models were run with the natural logarithm of CRP as the dependent variable. Models tested main effects, 2- and 3-way interactions of diabetes status, ethnicity, and gender with CRP. Clinically important adjustment variables: age, smoking, education, marital status, and health insurance were used. Other covariates considered, such as physical activity, fatty acid intake, and dietary fiber were not included since they were not significantly correlated with CRP. Energy (Kcal/d) was not used as a covariate since it was highly collinear with all of the obesity indicators.

\section{Results}

The general characteristics of the study population by ethnicity are shown in Table 1. Compared with African Americans, Haitian Americans were older, had lower obesity measures, lower CRP, less percent of current smokers, higher percent married, and had a lower percent with health care coverage. Both ethnicities were compared by diabetes status in Table 2. As compared to those free of diabetes, those with type 2 diabetes were older, had higher obesity measures, higher CRP and had a higher percent with less than a high school education. 
Citation: Huffman FG, Vaccaro JA, Rowe TM, Zarini GG, Sukharam SD, et al. (2014) Obesity Indicators and C - reactive Protein in African and Haitian Americans with and without Type 2 Diabetes. J Nutr Disorders Ther 4: 145. doi:10.4172/2161-0509.1000145

Page 3 of 6

Independent $\mathrm{t}$-test by ethnicity (data not shown) indicated that females had higher waist circumference and BMI than males, but that males had a higher waist to height ratio. In addition CRP levels were higher for females $(2.9 \pm 2.3)$ as compared to males $(2.3 \pm 2.2), \mathrm{P}=.007$. To assess the effect of ethnicity, diabetes status, and gender with obesity indicators on CRP, separate models were run (Table 3). Since the 2-and 3-way interactions were not significant, final models included main effects with each obesity indicator, adjusted for age, smoking, marital status, education, and health insurance. All differences in CRP by ethnicity and diabetes status were negated by obesity indicators. The proposed hypothesis that CRP levels would be higher for persons with diabetes independent of obesity was not supported. The second hypothesis, that Haitian Americans and African Americans would have different CRP levels was supported in the reduced model. Once obesity measures were added, the difference in CRP levels between these ethnicities was no longer significant.

\begin{tabular}{|c|c|c|c|}
\hline Variable & Haitian Americans & African Americans & $\mathbf{P}$ \\
\hline & \multicolumn{2}{|l|}{ Means \pm SD } & \\
\hline Age (yrs) & $56.2 \pm 11$ & $53.1 \pm 9.2$ & .002 \\
\hline Waist circumference $(\mathrm{cm})$ & $97.7 \pm 12$ & $106.5 \pm 17$ & $<.001$ \\
\hline Body mass index (BMI) $\left(\mathrm{kg} / \mathrm{m}^{2}\right)$ & $29.0 \pm 5.0$ & $32.5 \pm 7.3$ & $<.001$ \\
\hline Waist-to-height ratio & $.597 \pm .08$ & $.629 \pm .11$ & .001 \\
\hline \multirow[t]{2}{*}{ C-reactive protein (CRP) (mg/dL) } & $2.20 \pm 2.0$ & $3.13 \pm 2.4$ & $<.001$ \\
\hline & \multicolumn{2}{|l|}{$\mathrm{N}$ (\% within ethnicity) } & \\
\hline Gender (females) & $125(51.2)$ & $85(44.7)$ & .179 \\
\hline Type 2 diabetes (yes) & $130(53.3)$ & $100(52.6)$ & .893 \\
\hline Current smoker (yes) & $15(6.1)$ & $75(39.5)$ & $<.001$ \\
\hline Education (< high school) & $119(48.8)$ & $31(16.3)$ & $<.001$ \\
\hline Currently married/cohabitating (yes) & $154(63.1)$ & $52(27.4)$ & $<.001$ \\
\hline Health insurance in past year (yes) & $225(51.2)$ & $147(77.4)$ & $<.001$ \\
\hline
\end{tabular}

Table 1: General characteristics of the study population by ethnicity

\begin{tabular}{|c|c|c|c|}
\hline Variable & Without diabetes & With type 2 diabetes & $\mathbf{P}$ \\
\hline & \multicolumn{2}{|l|}{ Means \pm SD } & \\
\hline Age (yrs) & $52.8 \pm 9.8$ & $56.6 \pm 10$ & $<.001$ \\
\hline Waist circumference $(\mathrm{cm})$ & $97.7 \pm 13$ & $105 \pm 16$ & $<.001$ \\
\hline Body mass index $(\mathrm{BMI})\left(\mathrm{kg} / \mathrm{m}^{2}\right)$ & $29.3 \pm 5.4$ & $31.6 \pm 7.0$ & $<.001$ \\
\hline Waist-to-height ratio & $.585 \pm .08$ & $.634 \pm .10$ & $<.001$ \\
\hline \multirow[t]{2}{*}{ C-reactive protein $(\mathrm{CRP})(\mathrm{mg} / \mathrm{dL})$} & $2.29 \pm 2.1$ & $2.89 \pm 2.4$ & $<.001$ \\
\hline & \multicolumn{2}{|c|}{$\mathrm{N}$ (\% within diabetes status) } & \\
\hline Gender (females) & $95(46.6)$ & $115(50.0)$ & .475 \\
\hline Ethnicity (Haitian American) & $114(55.9)$ & $130(56.5)$ & .893 \\
\hline Current smoker (yes) & $44(21.6)$ & $46(20.0)$ & .687 \\
\hline Education (< high school) & $56(27.5)$ & $94(40.9)$ & .006 \\
\hline Currently married/cohabitating (yes) & $98(48.0)$ & $108(47.0)$ & .822 \\
\hline Health insurance in past year (yes) & $121(59.3)$ & $151(65.7)$ & .173 \\
\hline
\end{tabular}

Table 2: General characteristics of the study population by diabetes status 
Citation: Huffman FG, Vaccaro JA, Rowe TM, Zarini GG, Sukharam SD, et al. (2014) Obesity Indicators and C - reactive Protein in African and Haitian Americans with and without Type 2 Diabetes. J Nutr Disorders Ther 4: 145. doi:10.4172/2161-0509.1000145

Page 4 of 6

\begin{tabular}{|c|c|c|c|c|}
\hline Model & Independent Variables & Coefficient $(95 \% \mathrm{Cl})$ & SE & $\mathbf{P}$ \\
\hline Model 1 & Body mass index $(\mathrm{kg} / \mathrm{m} 2)$ & $1.83(1.3,3.2)$ & .25 & $<.001$ \\
\hline \multirow[t]{2}{*}{ Ethnicity } & Haitian American & $-.19(-.42,-.04)$ & .12 & .107 \\
\hline & African American (reference) & - & - & - \\
\hline \multirow[t]{2}{*}{ Diabetes status } & Without diabetes & $-.12(-.29, .07)$ & .09 & .230 \\
\hline & With diabetes (reference) & - & - & - \\
\hline \multirow[t]{2}{*}{ Gender } & Female & $.22(.03, .41)$ & .10 & .022 \\
\hline & Male (reference) & - & - & - \\
\hline Model 2 & Waist circumference $(\mathrm{cm})$ & $2.79(2.1,3.4)$ & .33 & $<.001$ \\
\hline \multirow[t]{2}{*}{ Ethnicity } & Haitian American & $-.15(-.37, .07)$ & .12 & .181 \\
\hline & African American (reference) & - & - & - \\
\hline \multirow[t]{2}{*}{ Diabetes status } & Without diabetes & $-.05(-.23, .13)$ & .09 & .600 \\
\hline & With diabetes (reference) & - & - & - \\
\hline \multirow[t]{2}{*}{ Gender } & Female & $.29(.11, .48)$ & .09 & .022 \\
\hline & Male (reference) & - & - & - \\
\hline Model 3 & Waist-to-height ratio & $2.8(2.2,3.5)$ & .33 & $<.001$ \\
\hline \multirow[t]{2}{*}{ Ethnicity } & Haitian American & $-.21(-.43, .007)$ & .11 & .057 \\
\hline & African American (reference) & - & - & - \\
\hline \multirow[t]{2}{*}{ Diabetes status } & Without diabetes & $-.05(-.23, .13)$ & .09 & .606 \\
\hline & With diabetes (reference) & - & - & - \\
\hline \multirow[t]{2}{*}{ Gender } & Female & $.11(-.08, .30)$ & .10 & .269 \\
\hline & Male (reference) & - & - & - \\
\hline
\end{tabular}

Table 3: General Linear Models for the effect of ethnicity, diabetes status, and gender with obesity indicators on C-reactive proteins

\section{Discussion}

These findings suggest that a high CRP level is related to obesity indicators for both Black ethnicities, Haitian and African Americans. Although African Americans had higher CRP levels as compared to Haitian Americans, this association was no longer significant, adjusting for obesity. Females had higher CRP than males, even when adjusting for obesity; however, once demographics were taken into account, gender was no longer associated with CRP. In addition, obesity indicators, waist circumference and BMI by race/ethnicity interactions were not associated with CRP in our study; however, waist circumference interacted with ethnicity and gender in predicting CRP levels in a nationally representative US sample [12]. Using BMI as an obesity indicator the investigators found higher BMI was significantly associated with higher CRP regardless of race/ethnicity for the national sample which agreed with our findings for both Haitian and African Americans. Conversely, Khera et al [11] found CRP levels that differed by race and gender were still significant even after adjusting for BMI for a multiethnic, large probability sample of participants from Dallas County, Texas. Despite the ethnic differences found in CRP levels, BMI was associated with CRP, independent of age in a multiethnic study of women [15]. Allowing for BMI as a confounder, these investigators found African ancestry to be independently associated with higher CRP as compared to Caucasian women; albeit, ethnic differences in CRP were substantially attenuated when adjusting for BMI [15]. Another possible confounder between race and obesity indicators with CRP levels could be due to differences in the type and amount of fat present for a given BMI or waist circumference. Stevens et al [16] found different health outcomes, such as diabetes, hypertension, and hyperlipidemia were found to have different associations with BMI by race for African American and Caucasian women. The investigators stated BMI cutoffs had different equivalent risk by race for different health outcomes and risk estimates [16]. Visceral adipose tissue, associated with metabolic abnormalities, has been found to be lower in African American men and women as compared to Caucasian men and women for a given BMI or waist circumference [17]. Racial/ethnic differences in visceral fat suggest obesity indicators such as waist circumference and BMI may over- or 
under-estimate health risk for certain groups and cutoffs may need to be specific by race/ethnicity $[16,17]$.

We did not find any differences in CRP by diabetes status accounting for obesity. Diabetes is another confounder in assessing the relationships among BMI, race/ethnicity and CRP. BMI has a strong correlation with CRP and may introduce a low grade of inflammation in a person with excess body fat, which can be an underlying factor in the pathogenesis of type 2 diabetes [6,7]. Huffman and colleagues [18] reported obesity was more associated with CRP in persons without as opposed to with type 2 diabetes in Cuban American adults. The investigators attribute diabetes medications as partially explaining their unexpected results since some oral hypoglycemic agents have been shown to reduce CRP levels $[19,20]$. Obesity may have been confounded by diabetes complications in assessing CRP differences for those with diabetes as compared to controls. Sarangi et al, [21] found higher CRP levels for the group with hypertension and retinopathy $(5.8 \pm 2.13 \mathrm{mg} / \mathrm{ml})$ disease as compared to the group without complications $(5.2 \pm 1.16)$ in non-obese Asian Indian males with type 2 diabetes $(\mathrm{N}=80)(\mathrm{P}=.019)$. The investigators also compared CRP levels in the combined group with diabetes $(5.1 \pm 2.59)$ with the control group (free of diabetes) $(1.7 \pm .54)(\mathrm{P}=.001)$.

Another possible confounder in assessing CRP differences across diabetes status and ethnicity could be genetic differences. The production of paraoxonase-I activity (PON 1), an enzyme functioning with high-density lipoprotein cholesterol (HDL-C) helps to protect low-density lipoprotein cholesterol (LDL-C) from oxidation, is influenced by genetic and environmental factors and may differ in persons with T2D [22]. Lower PON 1 (199 \pm 39 vs. $258 \pm 60 \mathrm{U} / \mathrm{L}$ $\mathrm{P}<0.05)$ and higher CRP $(5.8 \pm 4.9$ vs. $3.2 \pm 1.1 \mathrm{mg} / \mathrm{L}, \mathrm{P}<0.05)$ was found in a group with $\mathrm{T} 2 \mathrm{D}$ and diabetic retinopathy on oral antiglycemic agents as compared to controls free of diabetes in Asian Indian male and female outpatients $(\mathrm{N}=54)$ [22]. Even though both PON 1 and retinopathy have been associated with oxidative stress, there were no significant differences between the T2D groups with and without diabetic retinopathy [22].

Components of diet as well as overall diet quality may have been associated with CRP for our sample. Although we did not adjust for overall diet quality, we tested association with several notable dietary components known to be associated with CRP levels. The normalized variables for dietary fiber and CRP levels were not correlated for our participants. Our sample had lower than recommended dietary fiber intake regardless of diabetes status. A systematic review indicated in six out of seven intervention trials higher fiber dosages significantly lowered CRP from baseline to completion [23]. The relationship between saturated fatty acid intake and CRP was not significant for our participants. Studies comparing dietary saturated fatty acid and CRP levels have been inconsistent. The ratio of saturated to polyunsaturated fatty acids intake was associated with higher CRP levels for men but this relationship was not significant for women in a study of a Portuguese population $(\mathrm{N}=395)$ [24].

\section{Limitations}

The strength of this study was the comparison between two Black ethnicities in terms of diabetes status, obesity markers, and CRP which to our knowledge has not been assessed; albeit, the study has several limitations. The cross-sectional design of this study could not establish causality. Participants were from Miami-Dade County, Florida and may not be representative of African Americans and Haitian
Americans throughout the entire state or country. BMI, waist circumference, and waist-to-height ratio are proxy measures of obesity. Even though we eliminating participants with CRP levels above $10 \mathrm{mg} / \mathrm{dL}$; we assumed our participants' CRP levels measured cardiovascular inflammation. By using this threshold, we increased the likelihood of cardiovascular inflammation; however, some cases may have been attributed to non-cardiovascular inflammation.

\section{Conclusions}

Although African Americans had higher levels of CRP as compared to Haitian Americans, we found all indicators of obesity, BMI, waist circumference and waist-to-height ratio to be associated with high CRP levels regardless of ethnicity or diabetes status, adjusting for confounders. Being female was associated with higher CRP when adjusting confounders and two of the obesity indicators, BMI and waist circumference, but not waist-to-height ratio. To its merit, this study differentiated cardiovascular risk factors among two Black ethnicities that have been assessed as one group in many epidemiological studies.

\section{Practical Application}

Inflammation constitutes a serious health problem for minorities with high rates of obesity. Target interventions aimed at improving health behaviours to reduce obesity could help in reducing inflammation and potential cardiovascular diseases in this population. Future studies should be conducted in other ethnic/racial groups which include comparisons of obesity indicators with CRP and other inflammatory markers.

\section{Acknowledgments}

This study was funded by a grant from the National Institutes of Health: NIH/NIDDK \#1SC1DK083060-01 to corresponding author. The analyses, interpretations, and conclusions are those of the authors, however, and do not reflect the views or opinions of the National Institutes of Health.

\section{References}

1. Albert MA, Ridker PM (2006) C-reactive protein as a risk predictor: do race/ethnicity and gender make a difference? See comment in PubMed Commons below Circulation 114: e67-74.

2. Schiller JS, Lucas JW, Ward BW, Peregoy JA (2012) Summary health statistics for U.S. adults: National Health Interview Survey, 2010. See comment in PubMed Commons below Vital Health Stat 10 : 1-207.

3. Center for Disease and Prevention, CDC (2012) Summary Health Statistics for U.S. Adults: 2010. Table 31.

4. Flint AJ, Rexrode KM, Hu FB, Glynn RJ, Caspard H, et al. (2010) Body mass index, waist circumference, and risk of coronary heart disease: a prospective study among men and women. See comment in PubMed Commons below Obes Res Clin Pract 4: e171-171e181.

5. Soinio M, Marniemi J, Laakso M, Lehto S, Rönnemaa T (2006) Highsensitivity C-reactive protein and coronary heart disease mortality in patients with type 2 diabetes: a 7 -year follow-up study. See comment in PubMed Commons below Diabetes Care 29: 329-333.

6. Hu FB, Meigs JB, Li TY, Rifai N, Manson JE (2004) Inflammatory markers and risk of developing type 2 diabetes in women. See comment in PubMed Commons below Diabetes 53: 693-700.

7. Schulze MB, Rimm EB, Li T, Rifai N, Stampfer MJ, et al. (2004) Creactive protein and incident cardiovascular events among men with 
Citation: Huffman FG, Vaccaro JA, Rowe TM, Zarini GG, Sukharam SD, et al. (2014) Obesity Indicators and C - reactive Protein in African and Haitian Americans with and without Type 2 Diabetes. J Nutr Disorders Ther 4: 145. doi:10.4172/2161-0509.1000145

Page 6 of 6

diabetes. See comment in PubMed Commons below Diabetes Care 27: 889-894.

8. Ford ES (1999) Body mass index, diabetes, and C-reactive protein among U.S. adults. See comment in PubMed Commons below Diabetes Care 22: 1971-1977.

9. Yudkin JS, Stehouwer CD, Emeis JJ, Coppack SW (1999) C-reactive protein in healthy subjects: associations with obesity, insulin resistance, and endothelial dysfunction: a potential role for cytokines originating from adipose tissue? See comment in PubMed Commons below Arterioscler Thromb Vasc Biol 19: 972-978.

10. Bulló M, García-Lorda P, Megias I, Salas-Salvadó J (2003) Systemic inflammation, adipose tissue tumor necrosis factor, and leptin expression. See comment in PubMed Commons below Obes Res 11: 525-531.

11. Khera A, McGuire DK, Murphy SA, Stanek HG, Das SR, et al. (2005) Race and gender differences in C-reactive protein levels. See comment in PubMed Commons below J Am Coll Cardiol 46: 464-469.

12. Wee CC, Mukamal KJ, Huang A, Davis RB, McCarthy EP, et al. (2008) Obesity and C-reactive protein levels among white, black, and hispanic US adults. See comment in PubMed Commons below Obesity (Silver Spring) 16: 875-880.

13. Callaway CW, Chumlea WC, Bouchard C, Himes JH, Lohman TG, et al (1988) Circumferences; Lohman TG ,Roche AF, Martorell R, Eds.; Anthropometric standardization reference manual human kinetics: Champaign, IL, USA, pp. 39-54.

14. Roberts WL, Sedrick R, Moulton L, Spencer A, Rifai N (2000) Evaluation of four automated high-sensitivity C-reactive protein methods: implications for clinical and epidemiological applications. See comment in PubMed Commons below Clin Chem 46: 461-468.

15. Kelley-Hedgepeth A, Lloyd-Jones DM, Colvin A, Matthews KA, Johnston J, et al. (2008) Ethnic differences in C-reactive protein concentrations. See comment in PubMed Commons below Clin Chem 54: 1027-1037.

16. Stevens J, Juhaeri, Cai J, Jones DW (2002) The effect of decision rules on the choice of a body mass index cutoff for obesity: examples from African
American and white women. See comment in PubMed Commons below Am J Clin Nutr 75: 986-992.

17. Carroll JF, Chiapa AL, Rodriquez M, Phelps DR, Cardarelli KM, et al (2008) Visceral fat, waist circumference, and BMI: Impact of race/ ethnicity. Obesity 16(3):600-607.

18. Huffman FG, Whisner S, Zarini GG, Nath S (2010) Waist circumference and BMI in relation to serum high sensitivity C-reactive protein (hs$\mathrm{CRP}$ ) in Cuban Americans with and without type 2 diabetes. See comment in PubMed Commons below Int J Environ Res Public Health 7: 842-852.

19. Dandona P, Chaudhuri A, Ghanim H, Mohanty P (2009) Insulin as an anti-inflammatory and antiatherogenic modulator. See comment in PubMed Commons below J Am Coll Cardiol 53: S14-20.

20. Huang CC (2007) Treatment targets for diabetic patients on peritoneal dialysis: any evidence? See comment in PubMed Commons below Perit Dial Int 27 Suppl 2: S176-179.

21. Sarangi R, Padhi S, Mahapatra S, Bhumika N (2012) Serum nitric oxide metabolites and high sensitivity C-reactive protein are important biomarkers in non-obese, Indian type 2 diabetic males. Int J Diabetes Dev Ctries 32(3):163-168.

22. Budak YU, Akdogan M, Huysal K (2013) Relationship of PON1 activity and hsCRP concentration with disease status in patients with type 2 diabetes mellitus with and without retinopathy. Int J Diabetes Dev Ctries 33(1):40-45.

23. North CJ, Venter CS, Jerling JC (2009) The effects of dietary fibre on Creactive protein, an inflammation marker predicting cardiovascular disease. See comment in PubMed Commons below Eur J Clin Nutr 63: 921-933.

24. Santos S, Oliveira A, Casal S, Lopes C (2013) Saturated fatty acids intake in relation to C-reactive protein, adiponectin, and leptin: a populationbased study. See comment in PubMed Commons below Nutrition 29: 892-897. 